\title{
ATUAÇÃO DO ESTADO NA DINÂMICA GEOECONÔMICA DA REGIÃO CENTRO-OESTE: INVESTIMENTOS E TRANSFORMAÇÕES TERRITORIAIS A PARTIR DO AGRONEGÓCIO ${ }^{1}$
}

\author{
Eduardo von Dentz ${ }^{2}$
}

\section{Resumo}

A dinâmica geoeconômica da região Centro-Oeste do Brasil tem sido transformada, nas últimas décadas, em função da atuação do Estado, através de investimentos diretos em forma de crédito, programas de assistência técnica e políticas de ocupação e desenvolvimento agropecuário. Para analisar esse tema, o objetivo do presente artigo consiste em situar a importância das políticas do Estado no estímulo ao potencial do agronegócio do estado do Mato Grosso no contexto geoeconômico nacional da região Centro-Oeste. A metodologia usada para elaboração consistiu em quatro passos: revisão bibliográfica, levantamento de dados, trabalhos de campo/visitas técnicas, trabalhos técnicos e análise dos dados. Como resultado, constatou-se que a região Centro-Oeste se desenvolveu em muitos setores, com ênfase no econômico, todavia apresenta problemas a serem superados no agronegócio, sobretudo na desigualdade social.

Palavras-chave: Mato Grosso. Agronegócio. Atuação do Estado. Centro-Oeste.

\section{STATE PERFORMANCE IN THE GEOECONOMIC DYNAMICS OF THE MIDWEST REGION: INVESTMENTS AND TERRITORIAL TRANSFORMATIONS FROM AGRIBUSINESS}

\begin{abstract}
The dynamic geoeconomic of the Midwest region of Brazil has been transformed, in the last decades, depending of the State performance, thought direct investments in form of the credit, technical assistance programs and occupation politics and agricultural development. To analysis this case, the objective this article present is situate the importance of State politics in the incentive to the potential of agribusiness in Mato Grosso state, in the geoeconomic context national and the Midwest region. The methodology used to elaboration consist in four parts: literature review, data collection, fieldwork/technical visits, technical works and data analysis. As a result, it was found that region Midwest developed in many sectors, with emphasis on economic, but have a problem to be overcome in agribusiness and in specially in social inequality.
\end{abstract}

Key-words: Mato Grosso. Agribusiness. State action. Midwest.

\footnotetext{
${ }^{1}$ Este artigo é parte dos resultados da dissertação de mestrado defendida em fevereiro de 2018. Para sua elaboração contou-se com recursos oriundos da Coordenação de Aperfeiçoamento de Pessoa de Nível Superior CAPES.

${ }^{2}$ Graduado em Geografia (Licenciatura) - Universidade Federal da Fronteira Sul (UFFS) campus Chapecó (2015). Mestre em Geografia - Universidade Estadual do Oeste do Paraná (Unioeste) campus Francisco Beltrão (2018). Doutorando em Geografia - Universidade Federal de Santa Catarina (UFSC). Integrante do grupo de pesquisa da Unioeste: Dinâmica Econômica e Formação socioespacial. Integrante do grupo de pesquisa da UFSC: Formação Sócio Espacial: Progresso Técnico e Desenvolvimento Econômico (GEOTDE). E-mail: eduardovondentz@hotmail.com.
} 


\section{ACTUACIÓN DEL ESTADO EN LA DINÁMICA GEOECONÓMICA DE LA REGIÓN CENTRO-OESTE: INVESTIMENTOS Y TRANSFORMACIONES TERRITORIALES A PARTIR DEL AGRONEGOCIO}

\section{Resumen}

La dinamica geoeconómica de la región Centro-Oeste de Brasil ha sido transformada, en las últimas decadas, en función de la actuación del Estado, a través de investimientos directos en forma de credito, programas de assistencia técnica y políticas de ocupación y desarollo agropecuário. Para analisar ese tema, el objtivo del presente artículo es situar la importancia de las políticas del Estado en el estímulo al potencial del agronegócio del estado de Mato Grosso en el contexto geoeconómico nacional de la región Centro-Oeste. La metodología usada para elaboración del atículo se resume en cuatro: revisión bibliográfica, levantamiento de datos, trabajos de campo/visitas técnicas, trabajos técnicos y análisis de los datos. Como resultado, constatou-se que la región Centro-Oeste se desarolló en muchos sectores, sobretodo en el económico, todavía apresenta problemas que necessitan superación, en el agronegocio y sobretodo en la desiguadad social.

Palabras-clave: Mato Grosso. Agronegocio. Actuación del Estado. Centro-Oeste.

\section{INTRODUÇÃO}

Uma das questões importantes que pode ser levada em conta quando se abordam as características geoeconômicas de um dado espaço é em qual contexto esse recorte espacial (no caso, estado do Mato Grosso) encontra-se inserido. Por essa razão, considera-se como de fundamental importância abarcar, no contexto da dinâmica geoeconômica do estado do Mato Grosso, a formação geoeconômica da região Centro-Oeste como um todo, a partir do potencial econômico apresentado pelo Mato Grosso e pela região Centro-Oeste, em grande medida impulsionado pelos investimentos estatais. Dessa forma, o objetivo desse artigo é situar a importância das políticas do Estado no estímulo ao potencial do agronegócio ${ }^{3}$ do estado do Mato Grosso no contexto geoeconômico nacional da região Centro-Oeste. Metodologicamente, o artigo foi elaborado a partir de quatro passos: revisão bibliográfica,

\footnotetext{
${ }^{3}$ Diferentemente de uma vasta bibliografia que associa agronegócio à produção de commodities e o tamanho da área, definem-se, aqui, os agronegócios como uma cadeia produtiva "que envolve desde a fabricação de insumos, passando pela produção nos estabelecimentos agropecuários, pela transformação e o seu consumo final" (CONTINI et al., 2006, p. 6).
} 
levantamento de dados ${ }^{4}$, trabalhos e de campo/visitas técnicas ${ }^{5}$, trabalhos técnicos e análise dos dados.

De antemão, vale inferir que historicamente a concentração das atividades econômicas ocorrida sobretudo até a primeira metade do século XX, nas regiões litorâneas do Brasil, faz com que seja um desafio encontrar trabalhos de natureza científica específicos sobre cadeias produtivas do agronegócio na região Centro-Oeste, principalmente para falar do contexto geoeconômico da região no período que antecede o século XX. No entanto, os ciclos de desenvolvimento que podem ser pontuados na região Centro-Oeste, ao menos num contexto mais recente, são ligados aos investimentos feitos pelo Estado (DENTZ, 2018).

Do mesmo modo que diversos autores já apontaram, tal como Graziano da Silva (1998), Delgado (1985), Espindola e Cunha (2015) e Campos (2010), o Estado assumiu o papel de indutor da modernização ${ }^{6}$ e financeirização da agropecuária brasileira, através da montagem e do uso de um amplo sistema de incentivos financeiros e fiscais (SANTOS, 2016; DENTZ, 2018). A intensidade desse processo reflete no resultado dos benefícios da política estatal (crédito, assistência técnica, pesquisa, programas especiais, etc.) sobre os agentes hegemônicos, uma vez que os incentivos favoreceram a concentração acelerada da propriedade fundiária e da renda, permitindo lucros exorbitantes às multinacionais e aos grandes grupos econômicos nacionais e estrangeiros, além de sustentar o processo de ocupação, principalmente do Cerrado e da Amazônia.

Neste contexto, visando o alcance do objetivo anteposto, além desta introdução, dividimos o artigo em três principais tópicos: neste que segue abordamos o papel do Estado via BNDES na constituição econômica da região Centro-Oeste e do estado do Mato Grosso; no segundo tópico abordamos sobre o crescimento e a importância do setor de serviços como fundamental no atendimento às demandas do agronegócio na região Centro-Oeste e no estado do Mato Grosso. Por fim, no terceiro tópico, apresentamos as considerações finais.

\footnotetext{
${ }^{4}$ Os dados levantados foram buscados no sistema SIBRA do IBGE, na CONAB, nos boletins e relatórios do BNDES, no IMEA e no MAPA. Por se tratar de um texto que pretende demonstrar a atuação do Estado nos investimentos realizados na região Centro-Oeste, o BNDES foi mais acessado para busca dos dados.

${ }^{5}$ As visitas técnicas e trabalhos de campo foram realizados em outubro de 2016, na ocasião em que as informações vinham sendo coletadas para redação da dissertação de mestrado. Foram visitadas fazendas de produção de grãos, prefeituras (gestores públicos), centros de pesquisa e assistência técnica, dentre outros. Os trabalhos de campo aconteceram majoritariamente nos municípios de Lucas do Rio Verde e Sorriso, ambos no estado de Mato Grosso.

${ }^{6}$ Sobre a modernização da agricultura no Brasil, sabe-se que não ocorreu de forma homogênea, mas elevou significativamente os volumes produzidos e os valores movimentados. Ver mais em Graziano da Silva (1982; 1998).
} 


\section{O PAPEL DO ESTADO VIA POLÍTICAS PÚBLICAS E BNDES NA CONSTITUIÇÃO DA GEOECONOMIA DO CENTRO-OESTE E DO ESTADO DO MATO GROSSO}

O contexto histórico de investimentos realizados pelo governo federal na região Centro-Oeste aponta para alguns planos setoriais específicos colocados em prática pelo Estado ao longo dos anos (GUANZIROLI, 2006). No começo, decorrer das décadas de 1960, 1970 e 1980, o Estado impulsionou programas de colonização financiados e/ou incentivados desde o Ministério de Agricultura até os governos estaduais, objetivando ocupar as áreas tidas como promessas produtivas, sobretudo na região central do estado do Mato Grosso.

Nessa época, surgiram polos de colonização (privados e públicos do INCRA), que depois se transformaram em cidades importantes, como Sinop e Alta Floresta, no Norte do Mato Grosso, por exemplo. Dando sequência a este programa, o Governo Federal criou, em 1975, o Polocentro (Programa de Desenvolvimento da Região Centro-Oeste), como parte da ação regional do II PND (Plano Nacional de Desenvolvimento 1975-79). O objetivo era incorporar, de forma produtiva, aproximadamente 3,7 milhões de hectares de Cerrados (entre lavouras, pecuária e reflorestamento) nos estados do Mato Grosso, Mato Grosso do Sul, Goiás e nas regiões do Triângulo Mineiro, Alto Paranaíba, Alto e Médio São Francisco e Vão do Paracatu, todas no estado de Minas Gerais (SILVA, 2000; GUANZIROLI, 2006). Desse modo, percebe-se que o objetivo de ocupar a região Centro-Oeste está inserido num contexto maior de ocupação das áreas interioranas consideradas com potencial produtivo.

Essas áreas receberam recursos para investimentos em melhoria da infraestrutura e créditos subsidiados. Tratava-se de linhas de crédito fundiário, de investimento e de custeio a taxas de juros fixadas em níveis muito reduzidos e sem correção monetária. O Polocentro foi bem-sucedido por induzir a expansão da agricultura comercial no Cerrado. Estima-se que, entre 1975 e 1980, o programa tenha sido responsável pela incorporação direta de cerca de 2,4 milhões de hectares à agricultura (SILVA, 2000). Silva (2000) e Guanziroli (2006) apontam que foram beneficiados principalmente fazendeiros, proprietários de médios a grandes estabelecimentos. Entre 1975 e 1982, período no qual o programa esteve em vigor, foram aprovados 3.373 projetos, num montante total equivalente acerca de US\$ 350 milhões. Dos beneficiários, $81 \%$ operavam fazendas com áreas que variavam entre 200ha e 1000ha, absorvendo 88\% do volume total de crédito do programa (DENTZ, 2018).

Para substituir este programa, desativado em 1979, foi criado o Prodecer (Programa de Cooperação Nipo-brasileira para Desenvolvimento dos Cerrados) no início dos anos 1980. 
Segundo Silva (2000), o Prodecer é resultante do acordo de cooperação entre os governos brasileiro e japonês, estabelecido em 1976, pelo então Presidente Geisel, com a Japan International Cooperation Agency - JICA. Ademais, no ano de 1979, foi criada a Companhia de Promoção Agrícola - CAMPO, uma empresa mista de capital público e privado, tanto brasileiro quanto japonês, que tinha como objetivo planejar, assistir e coordenar o Prodecer. Os dados do próprio programa mostram que o montante de empreendimentos do Prodecer (fases I, II e III) foi de US\$ 570.000.000,00 e o objetivo inicial era incorporar ao processo produtivo uma área aproximada de 350.000 hectares de Cerrado em sete estados brasileiros: MG, GO, BA, MS, MT, TO e MA (GUANZIROLI, 2006; DENTZ, 2018).

Assim, no contexto histórico-geográfico da região Centro-Oeste e do estado do Mato Grosso, temos nos anos 1990 uma década conhecida nacionalmente como a década perdida, que estagnou o avanço das forças produtivas do agronegócio para o interior do Brasil. No entanto, a partir dos anos 2000, o BNDES (Banco Nacional de Desenvolvimento Econômico e Social) foi o principal veículo, na condição de instituição financeira pública, usado pelo Estado para promover o desenvolvimento territorial com elevados valores desembolsados. Os investimentos do BNDES foram realizados principalmente para contemplar projetos na área de infraestrutura (rodovias, ferrovias, estruturas para armazenamento da produção agrícola silos -, dentre outros), além do financiamento agrícola, usinas de geração de energia elétrica, sobretudo PCHs, dentre outros setores (DENTZ, 2018).

Neste sentido, vale inferir que, desde meados do século XIX, as regiões Sul e Sudeste do Brasil centralizaram expressivos investimentos em infraestrutura e na indústria, tendo alcançado uma infraestrutura superior às demais regiões. Neste contexto, pode-se afirmar que, historicamente, o discurso do governo foi pautado por preocupações com as diferenças regionais, sobretudo as diferenças sociais que ocorre entre as regiões. No entanto, muitas vezes em contexto de crise e de submissão às ordens externas, em grande medida devido aos pactos de poder de ordem internacional que ocorreram com as elites locais (BENJAMIN, 2012), o governo acabava dando ainda mais incentivos aos grandes grupos econômicos, o que contribuiu para a atenuação das desigualdades sociais. Pode-se dizer ainda que as políticas governamentais, embora de importância ímpar, não foram suficientes para alterar essa realidade e superar a condição de subdesenvolvimento do país como um todo, tendo em algumas circunstâncias, a gestão do Estado contribuído para o agravamento da desigualdade social e econômica internas (BNDES, 2014; DENTZ, 2018). 
Nessa ótica, como aponta o documento do BNDES (2014), já no contexto de execução das políticas do I e II PNDs, desde 1946 já era reforçado o objetivo de trazer as regiões mais pobres e atrasadas para um patamar de desenvolvimento similar ao da região Sul e Sudeste (BNDES, 2014). Neste sentido, a região Amazônica foi a primeira a ter atenção especial do governo, em função do movimento econômico gerado pelo ciclo da borracha. Esse aspecto, inclusive, contou com articulação geopolítica do governo brasileiro com os estadunidenses durante o período da Segunda Guerra Mundial, nos anos 1940. Nessa época foi fundado o Banco de Crédito da Borracha, que, mais tarde, nos anos 1960, se transformaria no Banco da Amazônia, visando o desenvolvimento dessas regiões "atrasadas" economicamente (BNDES, 2014).

$\mathrm{Na}$ área da promoção do desenvolvimento da região Amazônica, na qual o estado do Mato Grosso possui parte de sua área, no ano de 1953 foi criada a Superintendência do Plano de Valorização Econômica da Amazônia (SPVEA). Mesmo sem ter vingado, a criação desse projeto resultou numa importante contribuição para a criação de outra instituição, a Superintendência de Desenvolvimento da Amazônia (Sudam), em 1966. Considera-se importante abordar estes fatos históricos porque o desenvolvimento do estado do Mato Grosso, por exemplo, sobretudo a sua porção norte, que está próximo da Amazônia, foi, em alguns aspectos, influenciado pelas políticas adotadas para o desenvolvimento da Amazônia. No entanto, especificamente para a região Centro-Oeste, o marco mais importante ligado à sua transformação foi a construção de Brasília, na década de 1960. Esse fato fez parte de um plano estratégico do governo federal de transferir a capital do litoral para o interior do Brasil, sendo que isso representou a concretização de algumas preocupações, como o desenvolvimento econômico a partir da construção de novos complexos de infraestrutura rodoviária e da abertura de novas fronteiras de produção, sobretudo ligadas à agropecuária (DENTZ, 2018).

No âmbito da região Centro-Oeste, a Superintendência de Desenvolvimento do Centro-Oeste (Sudeco), criada em 1967, desempenhou papel fundamental no quesito da integração da economia regional com o contexto econômico nacional. Programas como o Polocentro criado em 1975 e a própria implantação das unidades da Embrapa na região Centro-Oeste, fizeram parte de um plano estratégico do governo de conhecer as peculiaridades da região, sobretudo do bioma Cerrado, a fim de incorporá-lo ao cenário produtivo nacional (BNDES, 2014). Embora tenha cumprido com seu papel, em 1990 a Sudeco foi extinta, mas voltou a existir em 2011, a partir das políticas implementadas pelos 
governos Lula e Dilma, com o objetivo específico de elaborar um plano regional de desenvolvimento para o Centro-Oeste, voltado principalmente para a redução das desigualdades regionais, ao incremento do potencial competitivo da economia regional, e à inclusão social (DENTZ, 2018).

Ademais, os sucessivos planos de desenvolvimento estratégicos aprovados pelo BNDES na década de 1990 e nos anos 2000 visavam, a todo momento, viabilizar investimentos que resultassem na criação de empregos, redução das desigualdades sociais e regionais e incorporação do desenvolvimento tecnológico (BNDES, 2014). No entanto, embora os desembolsos feitos pelo BNDES nos últimos anos tenham contribuído significativamente para o desenvolvimento do país, sabe-se que as desigualdades sociais e a concentração de renda persistem e são claramente visíveis nos diversos setores da economia, inclusive no agronegócio. Assim, a continuidade do trabalho que leva à correção dessas desigualdades sociais permanece como grande desafio do BNDES. Por isso, uma das estratégias adotadas pelo BNDES, dadas as dimensões e a diversidade de potencialidades econômicas existentes no Brasil e na região Centro-Oeste, foi apreender as diferentes características e diversidade intrínsecas a cada uma das regiões, assim como suas dinâmicas próprias e demandas específicas (BNDES, 2014).

Neste sentido, dada a importância do BNDES no quesito desenvolvimento econômico e social das regiões brasileiras, no que diz respeito à caracterização geoeconômica da região Centro-Oeste como um todo, o agronegócio tem respondido por parcelas cada vez maiores das exportações brasileiras. A região Centro-Oeste, com a expansão da fronteira agrícola e os avanços tecnológicos nas últimas décadas, em grande parte promovidos pela Embrapa, vislumbrou o desenvolvimento de uma moderna agropecuária, responsável pela elevação do Produto Interno Bruto nacional, tendo destaque a produção de grãos (soja e milho) e a pecuária bovina, suína e de aves (BNDES, 2014).

No entanto, embora o desempenho da economia do Centro-Oeste tenha repercutido positivamente no Brasil, esse dado não tem se expressado com a mesma intensidade nos indicadores sociais da região. Segundo o BNDES (2014), verificam-se muitas deficiências no acesso aos serviços pela população, o que, de modo geral, tem comprometido a qualidade de vida na região. Sobretudo nas últimas duas décadas, esses indicadores mostraram uma significativa melhora se comparado com outras regiões do Brasil, mas a situação ainda é marcada pelo alto grau de desigualdade verificado na distribuição dos rendimentos auferidos 
pela população. O efeito da construção de Brasília tem aumentado essa distorção na região, haja vista que a concentração de serviços de alto rendimento na capital federal fez com que a desigualdade possa ser verificada em maior discrepância com outras partes da região CentroOeste (DENTZ, 2018).

Ademais, a expressiva especialização territorial produtiva que ocorre na região CentroOeste tem provocado alguns desafios para o desenvolvimento da região, haja vista que uma parcela significativa da população está à margem desse processo de desenvolvimento econômico, "dado o padrão produtivo caracterizado pelo baixo valor agregado nas exportações, baixa diversificação econômica, elevada desigualdade social" (BNDES, 2014, p. 13). Nesta ótica, fica explícito que as políticas pensadas para promover o desenvolvimento da região Centro-Oeste não podem mais ser pensadas na perspectiva que culminaram as políticas da "Marcha para o Oeste" e na construção de Brasília, por exemplo. As políticas públicas de desenvolvimento mais recentes para a região Centro-Oeste, se considerarem as peculiaridades socioambientais e socioeconômicas da região como um ativo a ser potencializado, podem promover uma tipologia de desenvolvimento que privilegie não apenas as importantes questões relativas ao meio ambiente, mas também todas as camadas sociais da população, de modo a diminuir a desigualdade, para a qual chamamos atenção anteriormente (DENTZ, 2018).

Mesmo com todos os desafios apontados, de acordo com documento disponibilizado pelo BNDES (2014), o grande desafio para a região é a agregação de valor e a diversificação da base produtiva, sobretudo do agronegócio. O BNDES e o Ministério da Integração Nacional têm corroborado insistentemente com essa perspectiva em seus projetos, estudos e planos. Todos os esforços realizados neste âmbito resultaram números crescentes em diversos indicadores sociais e econômicos para a região Centro-Oeste. De acordo com o BNDES (2014), enquanto no período 1960-2010 a taxa de crescimento do Brasil foi, em média, de $2,01 \%$ ao ano, na região Centro-Oeste essa média chegou a 3,42\% de crescimento ao ano. Esse crescimento econômico elevado também fez com que a participação da região CentroOeste no PIB brasileiro saísse de algo em torno de 2\% em 1960 para 9,3\% em 2010, como pode ser visto no Gráfico um (DENTZ, 2018). 


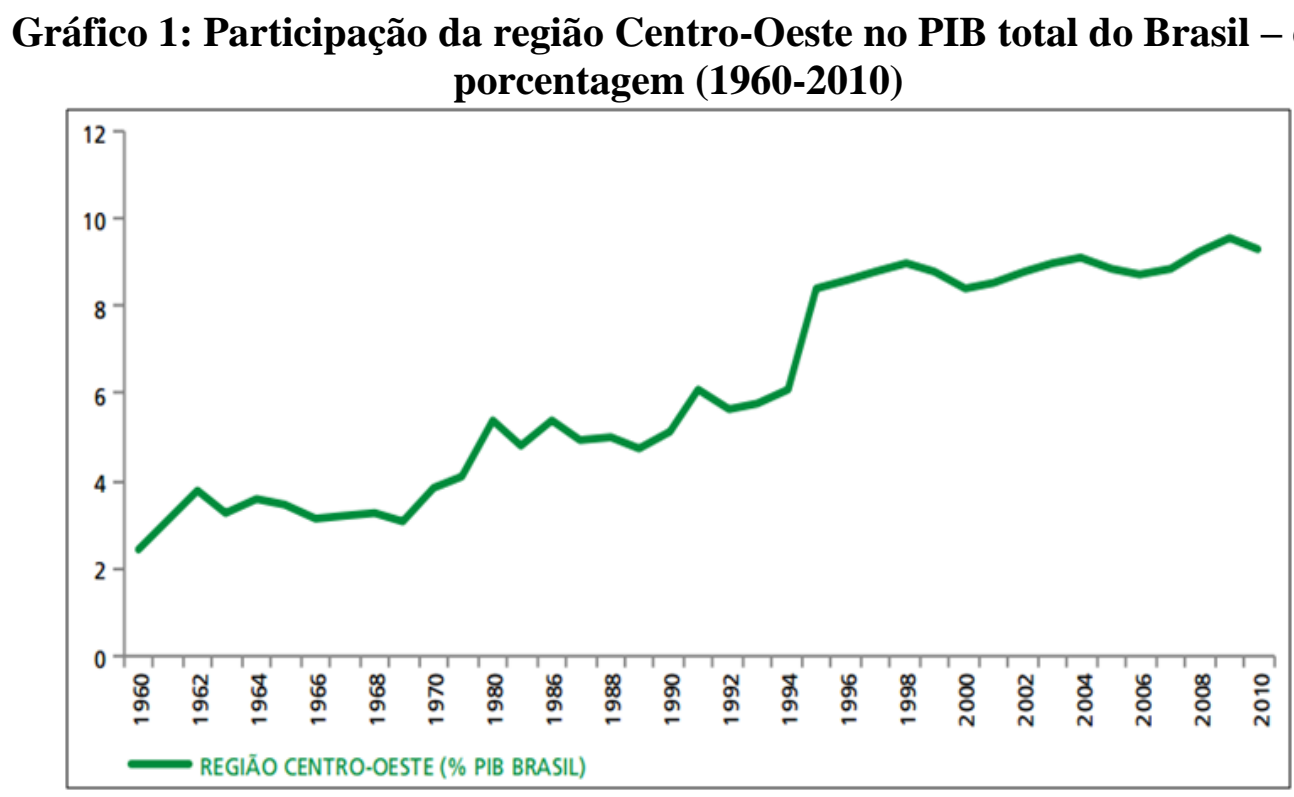

Fonte: IBGE, 2010. BNDES, 2014. Organizado pelo autor.

No tópico a seguir, apresentamos alguns dados sobre a importância, juntamente com o agronegócio e a indústria, do setor de serviços para a movimentação da economia do estado do Mato Grosso e da região Centro-Oeste. Assim, percebemos que o melhoramento dos índices de representação econômica da região Centro-Oeste e do estado de Mato Grosso, se dão em função de um importante crescimento do setor de serviços, muitas vezes atrelado ao agronegócio, que comanda a parcela significativa, inclusive das atividades que se desenvolvem nos serviços. Estas atividades podem ser caracterizadas, para o caso do Mato Grosso, como agroserviços.

\section{O SETOR DE SERVIÇOS QUE ATENDE AS DEMANDAS DO AGRONEGÓCIO NA REGIÃO CENTRO-OESTE E NO ESTADO DO MATO GROSSO}

Nesta ótica, no que diz respeito à importância do setor agropecuário na composição do PIB da região Centro-Oeste, o Gráfico 2 mostra que o referido setor é o menos importante na composição da economia dessa região no período mais recente. No entanto, a importância do agronegócio vai além da sua pequena representatividade no PIB da região Centro-Oeste (Gráfico 2). Isso porque grande parte da produção industrial dessa região, sobretudo do estado do Mato Grosso, está atrelada ao agronegócio. O Centro-Oeste como um todo possui uma dinâmica na qual, em muitas cidades onde o agronegócio se destaca, a infraestrutura de transporte acompanha esse desenvolvimento e, consequentemente, a economia voltada para o agronegócio atrai empresas comerciais e transformadoras dos produtos gerados no campo. 
Dessa forma, na medida em que a base produtiva agropecuária ocupa o cenário econômico da região Centro-Oeste, inicia-se um processo de diversificação do setor industrial e de expansão do setor de serviços (BNDES, 2014; DENTZ, 2018). No caso específico do setor de serviços, o mais representativo dos três (Gráfico 2), muitas de suas atividades são totalmente atreladas as demandas agropecuárias.

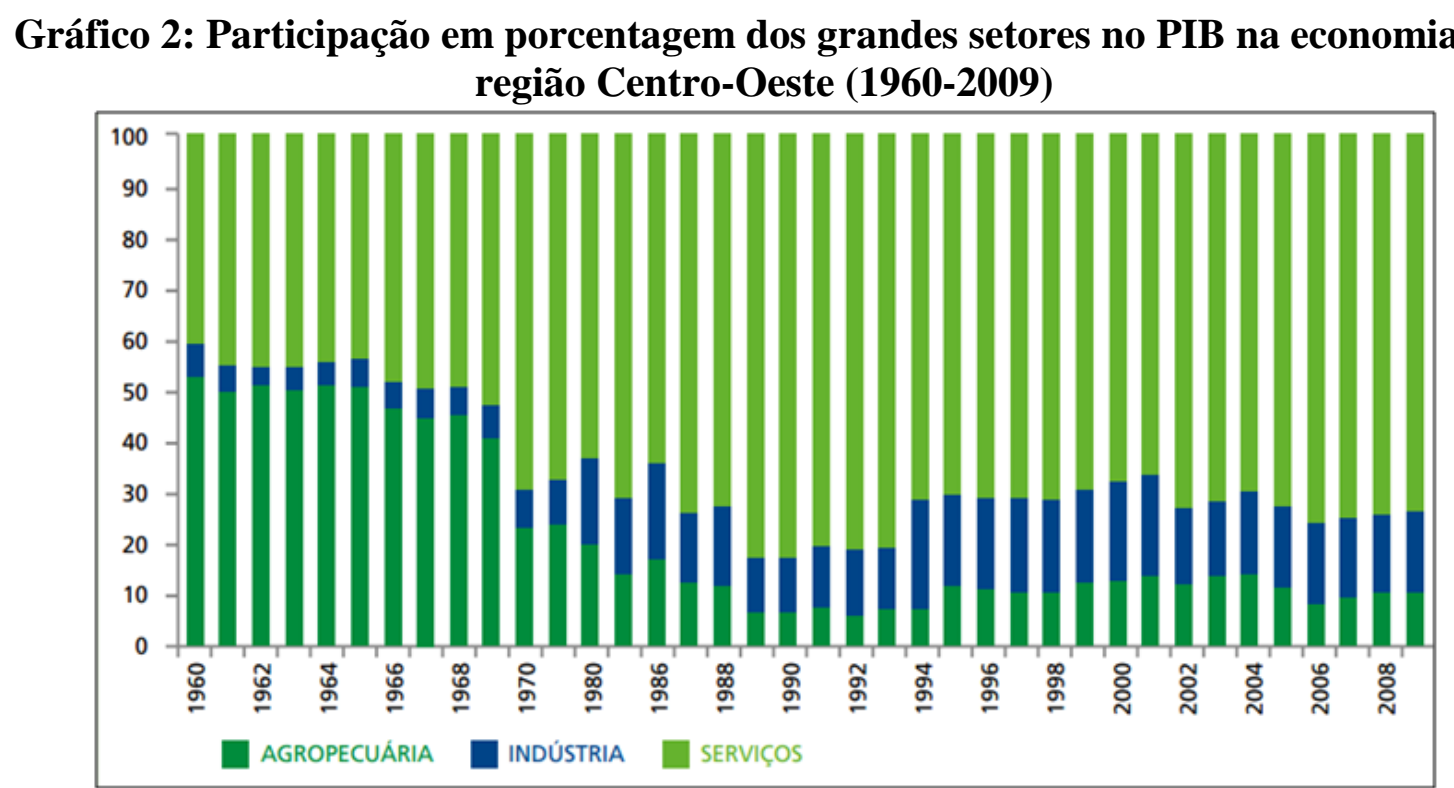

Fonte: IBGE, 2010. BNDES, 2014. Organizado pelo autor.

Podemos afirmar que o crescimento no setor de serviços, tal como é demonstrado na região Centro-Oeste através do Gráfico 2, é uma tendência que ocorre em todo o Brasil. No entanto, a região Centro-Oeste merece destaque para o fato da participação do setor público como componente nos serviços ser bastante expressivo (o crescimento no comércio em geral, atacados, serviços públicos relacionados à saúde, educação e segurança pública, por exemplo, também merecem destaque). De acordo com BNDES (2014), só em 2009 a participação dos serviços no total do PIB foi de $73 \%$, sendo que desses, $43 \%$ eram derivados do setor público. Dentre todas as regiões do Brasil, a região Centro-Oeste é a que tem maior participação do setor público na parcela do PIB de serviços (DENTZ, 2018).

Com esse dado, é possível dar destaque à ampliação no fornecimento de serviços públicos da rede federal no estado do Mato Grosso. Só nos serviços ligados à educação pública federal, deve-se considerar que o Instituto Federal do Mato Grosso (IFMT) e a Universidade Federal do Mato Grosso (UFMT), depois de um processo de expansão dos campi nos anos 2000, marcam presença mesmo nas áreas mais remotas do estado. Ao todo 
são quatorze campi e cinco campi avançados do IFMT espalhados pelo estado, o que totaliza dezenove representações do IFMT no total. Além disso, é interessante destacar que vários campi do IFMT oferecem cursos técnicos, tecnólogos, profissionalizantes, superior e de pósgraduação ligados ao agronegócio. O levantamento que se apresenta no Quadro 1 sintetiza a diversidade de cursos ligados ao agronegócio disponíveis nos campi do IFMT (DENTZ, 2018).

Quadro 1: Oferta de cursos ligados ao agronegócio nos campi do IFMT (2017).

\begin{tabular}{|c|c|c|}
\hline $\begin{array}{l}\text { Campus do IFMT que } \\
\text { oferecem os cursos }\end{array}$ & Modalidade do curso & Nome do curso \\
\hline \multirow{4}{*}{ Alta Floresta } & \multirow[t]{2}{*}{ Superior } & Bacharelado em Administração \\
\hline & & Bacharelado em Zootecnia \\
\hline & \multirow{2}{*}{$\begin{array}{l}\text { Técnico Integrado ao Ensino } \\
\text { Médio }\end{array}$} & Técnico em Logística \\
\hline & & Técnico em Agropecuária \\
\hline \multirow{3}{*}{ Pontes e Lacerda } & Superior & Tecnologia em Comércio \\
\hline & \multirow{2}{*}{ Integrado ao Ensino Médio } & \\
\hline & & $\begin{array}{l}\text { Técnico em Controle Ambiental } \\
\text { Técnico em Comércio }\end{array}$ \\
\hline \multirow[t]{2}{*}{ Barra do Garças } & \multirow{2}{*}{$\begin{array}{l}\text { Técnico Integrado ao Ensino } \\
\text { Médio }\end{array}$} & Técnico em Alimentos \\
\hline & & Técnico em Comércio \\
\hline \multirow{6}{*}{ Cáceres } & \multirow[t]{2}{*}{ Superior } & Tecnologia em Biocombustíveis \\
\hline & & $\begin{array}{l}\text { Bacharelado em Engenharia } \\
\text { Florestal }\end{array}$ \\
\hline & \multirow{3}{*}{$\begin{array}{l}\text { Técnico Subsequente ao } \\
\text { Ensino Médio }\end{array}$} & Técnico em Agroindústria \\
\hline & & Técnico em Agropecuária \\
\hline & & Técnico em Florestas \\
\hline & $\begin{array}{l}\text { Técnico Integrado ao Ensino } \\
\text { Médio }\end{array}$ & Técnico em Agropecuária \\
\hline \multirow{6}{*}{ Campo Novo do Parecis } & \multirow[t]{2}{*}{ Superior } & Bacharelado em Agronomia \\
\hline & & Tecnologia em Agroindústria \\
\hline & \multirow{2}{*}{$\begin{array}{l}\text { Técnico Integrado ao Ensino } \\
\text { Médio }\end{array}$} & Técnico em Comércio \\
\hline & & Técnico em Agropecuária \\
\hline & \multirow{2}{*}{$\begin{array}{l}\text { Técnico Subsequente ao } \\
\text { Ensino Médio }\end{array}$} & Técnico em Comércio \\
\hline & & Técnico em Agropecuária \\
\hline \multirow{4}{*}{ Confresa } & \multirow[t]{2}{*}{ Superior } & Bacharelado em Agronomia \\
\hline & & $\begin{array}{l}\text { Licenciatura } \\
\text { Agrícolas }\end{array}$ \\
\hline & \multirow{2}{*}{$\begin{array}{c}\text { Técnico Integrado ao Ensino } \\
\text { Médio }\end{array}$} & Técnico em Alimentos \\
\hline & & Técnico em Agropecuária \\
\hline Rondonópolis & $\begin{array}{l}\text { Técnico Integrado ao Ensino } \\
\text { Médio }\end{array}$ & Técnico em Alimentos \\
\hline \multirow{5}{*}{ Cuiabá } & \multirow[t]{2}{*}{ Superior } & $\begin{array}{l}\text { Tecnologia } \\
\text { Geoprocessamento }\end{array}$ \\
\hline & & $\begin{array}{l}\text { Tecnologia em Controle de } \\
\text { Obras }\end{array}$ \\
\hline & \multirow[t]{2}{*}{ Integrado ao Ensino Médio } & Técnico em Eventos \\
\hline & & Técnico em Agrimensura \\
\hline & Subsequente em Ensino & Técnico em Agrimensura \\
\hline
\end{tabular}


Atuação do estado na dinâmica geoeconômica da região Centro-Oeste:

\begin{tabular}{|c|c|c|}
\hline & Médio & \\
\hline \multirow{4}{*}{ São Vicente (Campo Verde) } & Superior & Bacharelado em Agronomia \\
\hline & & Bacharelado em Zootecnia \\
\hline & & Tecnologia em Alimentos \\
\hline & $\begin{array}{c}\text { Técnico Integrado ao Ensino } \\
\text { Médio }\end{array}$ & Técnico em Agropecuária \\
\hline \multirow{6}{*}{ Cuiabá (Bela Vista) } & Pós-graduação & Mestrado em Ciência \\
\hline & & Tecnologia dos Alimentos \\
\hline & Superior & $\begin{array}{l}\text { Bacharelado em Engenharia de } \\
\text { Alimentos }\end{array}$ \\
\hline & & $\begin{array}{lll}\text { Tecnologia em } & \text { Gestão } \\
\text { Ambiental } & & \\
\end{array}$ \\
\hline & $\begin{array}{l}\text { Técnico Subsequente ao } \\
\text { Ensino Médio }\end{array}$ & Técnico em Alimentos \\
\hline & $\begin{array}{l}\text { Técnico integrado ao Ensino } \\
\text { Médio }\end{array}$ & Técnico em Meio Ambiente \\
\hline \multirow{5}{*}{ Juína } & Superior & Tecnologia em Agronegócio \\
\hline & Técnico Integrado ao Ensino & Técnico em Meio Ambiente \\
\hline & Médio & Técnico em Agropecuária \\
\hline & & Técnico em Comércio \\
\hline & $\begin{array}{c}\text { Técnico Subsequente ao } \\
\text { Ensino Médio }\end{array}$ & Técnico em Agrimensura \\
\hline Lucas do Rio Verde & $\begin{array}{c}\text { Técnico Integrado ao Ensino } \\
\text { Médio }\end{array}$ & Técnico em Biotecnologia \\
\hline \multirow[t]{2}{*}{ Primavera do Leste } & Técnico Integrado ao Ensino & Técnico em Eletromecânica \\
\hline & Médio & Técnico em Logística \\
\hline \multirow{5}{*}{ Sorriso } & Superior & Bacharelado em Agronomia \\
\hline & & $\begin{array}{l}\text { Tecnologia em Produção de } \\
\text { grãos }\end{array}$ \\
\hline & & $\begin{array}{l}\text { Tecnologia em Gestão } \\
\text { Ambiental }\end{array}$ \\
\hline & Técnico Integrado ao Ensino & Técnico em Alimentos \\
\hline & $\begin{array}{r}\text { Médio } \\
\end{array}$ & Técnico em Agropecuária \\
\hline Várzea Grande & $\begin{array}{l}\text { Técnico Integrado ao Ensino } \\
\text { Médio }\end{array}$ & Técnico em Logística \\
\hline
\end{tabular}

Fonte: IFMT, (2017). Elaborado pelo autor.

Uma das questões importantes a ser ressaltada ao analisar o Quadro 1 é que, dos 19 campi do IFMT, 15 oferecem cursos ligados à área do agronegócio. Ou seja, nota-se, neste dado, que o Instituto Federal do Mato Grosso, cumpre um papel importante de desenvolvimento local e regional a partir do potencial econômico de cada região. Apesar de a maioria das unidades do IF do Mato Grosso serem recentes - grande parte delas foram criadas a partir do programa de expansão dos IFs, realizado no período do governo Lula - nota-se sua importância na formação de mão de obra qualificada e no desenvolvimento de ensino, pesquisa e extensão ligados, principalmente, às particularidades econômicas de cada região (DENTZ, 2018). 
Ademais, com a sistematização apresentada no Quadro 1 também é possível notar que o governo federal, a partir da atuação dos institutos federais, no caso do IFMT, tem o objetivo de capacitar gente para trabalhar no agronegócio do Mato Grosso. Na grande maioria dos cursos ofertados, independente de seus níveis, nota-se que a pessoa formada no curso sai apta a exercer sua função. Ou seja, há uma preocupação do governo em formar mão de obra capacitada para atuar nos diferentes segmentos do agronegócio do Mato Grosso. Vale lembrar que o levantamento do Quadro 1 apenas considera a oferta de cursos do IFMT ligados ao agronegócio, sendo que existem muitas outras instituições públicas e privadas que também trabalham para formar mão de obra qualificada para atuar no agronegócio. Ademais, o IFMT oferta cursos em outras áreas e não apenas nesta que damos ênfase.

No Quadro 2 é possível observar a atuação da Universidade Federal do Mato Grosso no mesmo sentido apresentado para o IFMT. Com isso, é possível traçar um paralelo com o que foi apontado quando se abordou a composição do PIB da região Centro-Oeste no tripé agropecuária-indústria-serviços. Ou seja, o setor de serviços que possui mais de $70 \%$ da participação na economia da região Centro-Oeste, na verdade, muitas vezes atua em prol do fortalecimento do agronegócio, como é o caso dos IFs e em grande parte da UFMT (Quadro 2). Os IFs entram no PIB como serviço público, portanto, fazem parte da parcela do PIB que diz respeito ao setor de serviços; no entanto, formam mão de obra qualificada justamente para atender as demandas do agronegócio. Por essa razão, a pequena porcentagem da agropecuária que aparece na composição do PIB do Gráfico 2 precisa ser relativizada e precisa ir além do que apenas os números apontam. Há, na verdade, uma interrelação entre os setores da economia, o que permite que, em muitas oportunidades, façam-se conexões entre os setores, como é caso do exemplo citado pelo serviço prestado no IFMT. Com essa reflexão, apresentamos no Quadro dois a atuação da UFMT nos cursos ofertados inerentes às atividades agropecuárias (DENTZ, 2018). 
Atuação do estado na dinâmica geoeconômica da região Centro-Oeste:

Quadro 2: Oferta de cursos ligados ao agronegócio nos campi da UFMT (2017)

\begin{tabular}{|c|c|c|}
\hline $\begin{array}{l}\text { Campus da UFMT que } \\
\text { oferecem os cursos }\end{array}$ & $\begin{array}{l}\text { Modalidade dos } \\
\text { cursos }\end{array}$ & Nome dos cursos \\
\hline \multirow{24}{*}{ Campus Cuiabá } & Superior & $\begin{array}{llllll}\text { Bacharelado em } & \text { Administração } & \text { com ênfase em } \\
\text { Agronegócio } & & & & \end{array}$ \\
\hline & & Bacharelado em Agronomia \\
\hline & & Bacharelado em Ciência e Tecnologia de Alimentos \\
\hline & & Bacharelado em Engenharia Florestal \\
\hline & & Bacharelado em Medicina Veterinária \\
\hline & & Bacharelado em Zootecnia \\
\hline & $\begin{array}{l}\text { Pós-graduação } \\
\text { Lato Sensu }\end{array}$ & $\begin{array}{l}\text { Especialização em Pequenos Animais nas áreas de } \\
\text { concentração Clínica, Cirurgia, Anestesiologia e } \\
\text { Diagnóstico por Imagem }\end{array}$ \\
\hline & & Especialização em Gestão na Indústria Sucroalcooleira \\
\hline & & Especialização em Solos: fertilidade e manejo \\
\hline & & $\begin{array}{l}\text { Especialização em Executivo em Gestão Avançada de } \\
\text { Negócios }\end{array}$ \\
\hline & & Especialização em Direito Agroambiental \\
\hline & & $\begin{array}{l}\text { Especialização em Clínica Médica e Cirúrgica de } \\
\text { Pequenos Animais, Anestesiologia, Diagnóstico por } \\
\text { Imagem e Patologia Clínica }\end{array}$ \\
\hline & & Especialização/MBA em Mercados e capitais \\
\hline & & $\begin{array}{l}\text { Especialização em Clínica e Cirurgia de Pequenos } \\
\text { Animais }\end{array}$ \\
\hline & & $\begin{array}{l}\text { Especialização em Processamento Pós-colheita de grãos } \\
\text { e sementes }\end{array}$ \\
\hline & Pós-graduação & Mestrado em Agronegócio e Desenvolvimento Regional \\
\hline & Stricto Sensu & Mestrado e doutorado em Ciência Animal \\
\hline & & Mestrado e doutorado em Agricultura Tropical \\
\hline & & Mestrado e doutorado em Ciências Veterinárias \\
\hline & & Mestrado em Direito Agroambiental \\
\hline & & Mestrado em Engenharia Agrícola \\
\hline & & Mestrado em Agronomia \\
\hline & & Mestrado em Zootecnia \\
\hline & & Mestrado em Nutrição, alimentos e metabolismo \\
\hline \multirow{6}{*}{ Campus Rondonópolis } & Superior & Bacharelado em Administração \\
\hline & & Bacharelado em Ciências Contábeis \\
\hline & & Bacharelado em Engenharia Agrícola e Ambiental \\
\hline & & Bacharelado em Zootecnia \\
\hline & Pós-graduação & Especialização em Tecnologia Ambiental \\
\hline & Lato Sensu & MBA em Planejamento Financeiro \\
\hline \multirow{4}{*}{$\begin{array}{lll}\text { Campus } & \text { Pontal do } \\
\text { Araguaia } & & \end{array}$} & Superior & Bacharelado em Agronomia \\
\hline & & Bacharelado em Engenharia de Alimentos \\
\hline & Pós-graduação & Mestrado em Gestão e Planejamento Ambiental \\
\hline & Stricto Sensu & Mestrado em Engenharia Agrícola \\
\hline \multirow{6}{*}{ Campus Sinop } & Superior & Bacharelado em Agronomia \\
\hline & & Bacharelado em Engenharia Agrícola e Ambiental \\
\hline & & Bacharelado em Engenharia Florestal \\
\hline & & Medicina Veterinária \\
\hline & & Bacharelado em Zootecnia \\
\hline & $\begin{array}{l}\text { Pós-graduação } \\
\text { Stricto Sensu }\end{array}$ & Mestrado em Agronomia \\
\hline
\end{tabular}


Da mesma forma que se analisou para o IFMT, Quadro 1, no Quadro 2 pode ser analisado o papel da Universidade Federal do Mato Grosso não apenas na formação de mão de obra qualificada, mas também no desenvolvimento da pesquisa ligada ao agronegócio. Tanto é assim que um dos pontos que salta aos olhos, ao analisar-se o Quadro 2, é o grande número de cursos de pós-graduação oferecidos pela UFMT que possuem alguma relação com o agronegócio. A universidade tem uma proposta diferente dos institutos federais, focando exclusivamente na oferta de cursos superior e de pós-graduação. Sendo assim, embora a UFMT tenha apenas cinco campi espalhados pelo estado, a oferta de cursos de graduação e pós-graduação ligados a alguma linha de pesquisa inerente ao agronegócio é significativo, ocorrendo em quatro dos cinco campi. Ao todo são 12 programas de mestrado e doutorado que a universidade oferece, na área do agronegócio, o que demonstra a importância da pesquisa para o desenvolvimento e a inovação neste setor. A maioria dos programas está concentrada no campus Cuiabá, o mais antigo da universidade. Mesmo assim, é importante pontuar que a descentralização da oferta dos cursos vem ocorrendo com a ampliação, datada na década de 2000, dos campi de Sinop, Rondonópolis e Pontal do Araguaia.

As análises e sistematizações apresentadas nos Quadros 1 e 2 são exemplos da importância do papel das fontes de crédito públicas na indução do desenvolvimento da região Centro-Oeste. Daí novamente a importância do papel do BNDES no desenvolvimento do Centro-Oeste, haja vista que foi a instituição financeira pública que realizou, nos últimos anos, significativos desembolsos para viabilização do crescimento econômico da região. O Gráfico 3 aponta para o montante desses investimentos realizados na região Centro-Oeste nos últimos anos (DENTZ, 2018). 


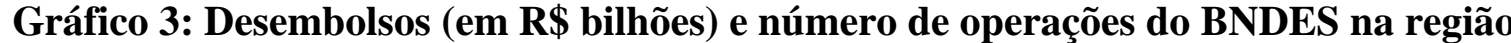
Centro-Oeste (2005-2013)

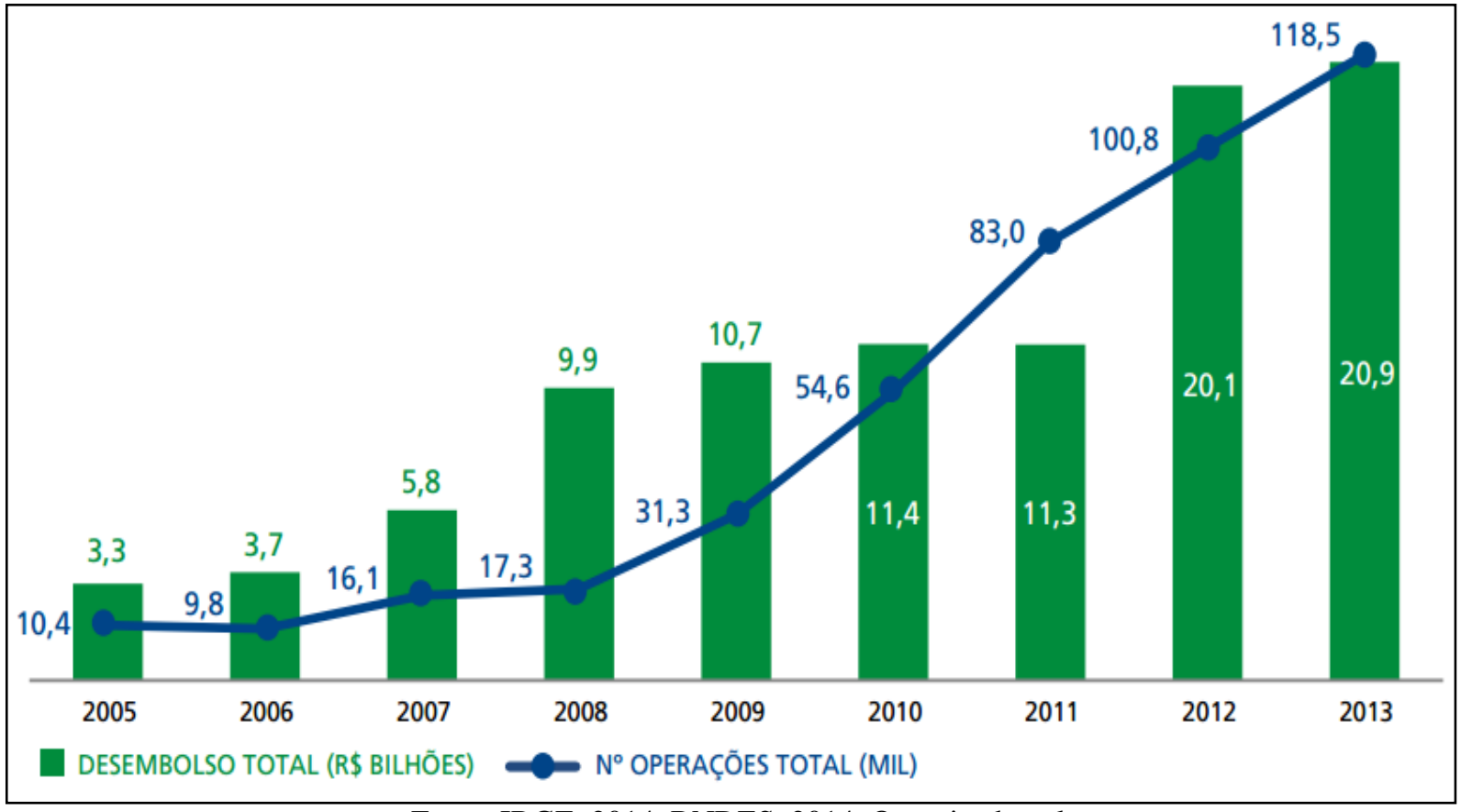

Fonte: IBGE, 2014. BNDES, 2014. Organizado pelo autor.

Como pode ser visto no Gráfico 3, o BNDES saiu de pouco mais de 10 mil operações em 2005 para mais de 118 mil operações em 2013. Neste mesmo período, os desembolsos do banco em 2005 giraram em torno de 3,3 bilhões de reais, sendo que chegou a quase 30 bilhões em 2013. Esses valores são responsáveis por boa parte das mudanças territoriais ocorridas na região Centro-Oeste nos últimos anos. Vale salientar que dentre as fontes de crédito públicas disponíveis para todo o país, o BNDES possui papel estratégico, como apontado no Gráfico três. A participação do Centro-Oeste nos desembolsos totais do banco realizados em todo o Brasil subiu de 7\% em 2005, para 11\% em 2013 (BNDES, 2014).

No que diz respeito aos desembolsos do BNDES por unidade da federação da região Centro-Oeste (Gráfico 4), nota-se uma variação entre os estados, com destaque para os desembolsos realizados nos estados de Goiás e Mato Grosso. 
Gráfico 4: Porcentagem de desembolsos do BNDES por estado da região Centro-Oeste (2005-2013).

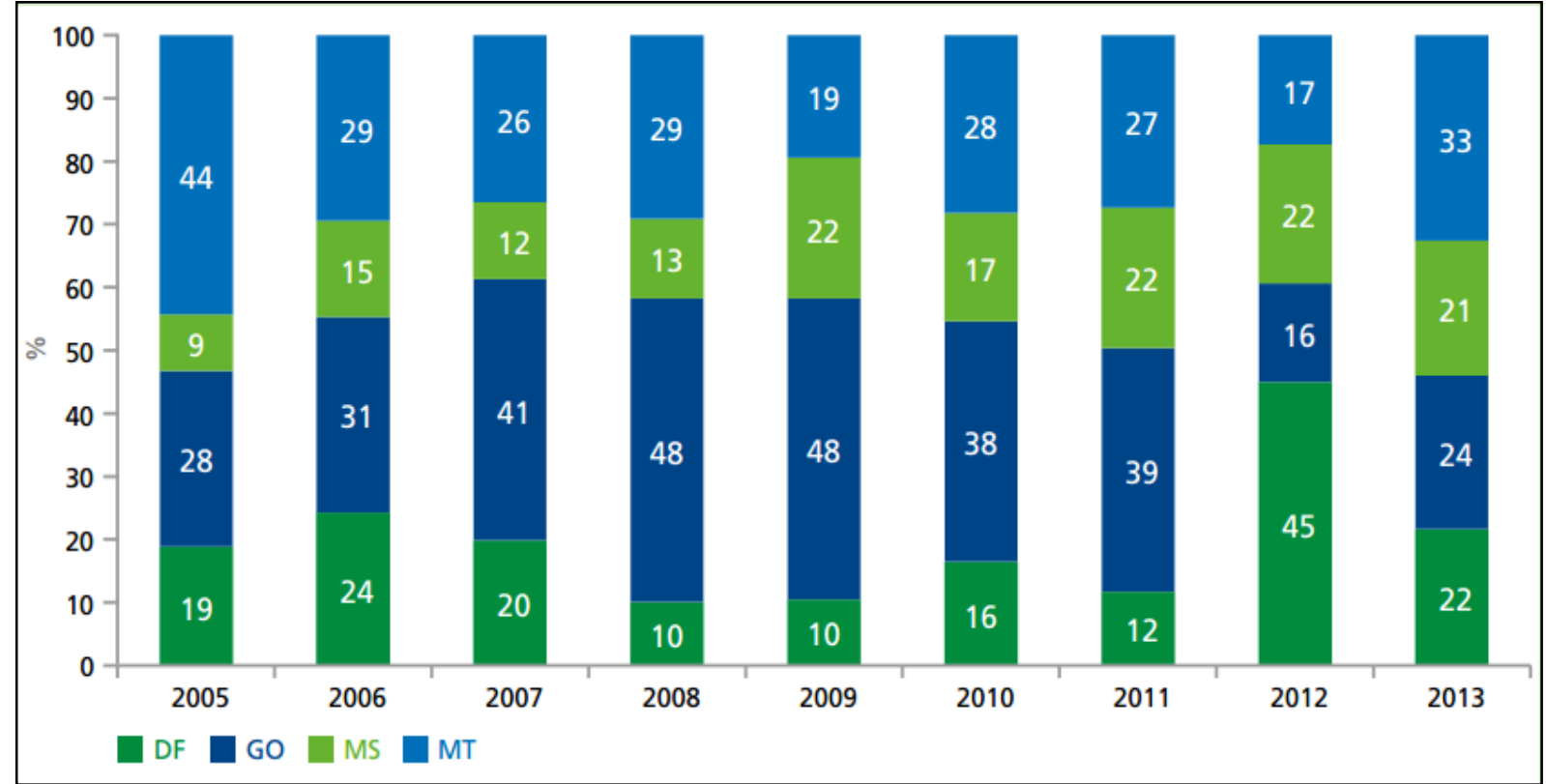

Fonte: IBGE, 2014. BNDES, 2014. Organizado pelo autor.

Com relação à distribuição dos desembolsos do BNDES por estado da região CentroOeste, o Gráfico 5 aponta que, de 2006 a 2011, o estado de Goiás foi o que recebeu a maior porcentagem dos desembolsos. O estado do Mato Grosso, em geral, vem em segundo lugar, tendo recebido em 2005, 44\% dos desembolsos do BNDES para a região Centro-Oeste. Embora seja possível afirmar que historicamente o estado de Goiás foi contemplado com maior parcela dos desembolsos do BNDES, em função de sua maior diversificação do setor industrial, mais recentemente projetos ligados aos agronegócios (celulose, fertilizantes agrícolas, infraestrutura e agroindústrias), têm equilibrado os desembolsos do BNDES, tendo os estados do Mato Grosso e Mato Grosso do Sul, além do Distrito Federal, nos últimos anos, recebido uma importância equilibrada se comparada ao estado de Goiás (Gráfico 4) (DENTZ, 2018).

Dada a distribuição dos desembolsos da região Centro-Oeste por (Gráfico 4), o Gráfico cinco apresenta a porcentagem dos desembolsos do BNDES por áreas de investimento. 
Gráfico 5: Porcentagem dos desembolsos do BNDES por setor de investimento na região Centro-Oeste (2005-2013)

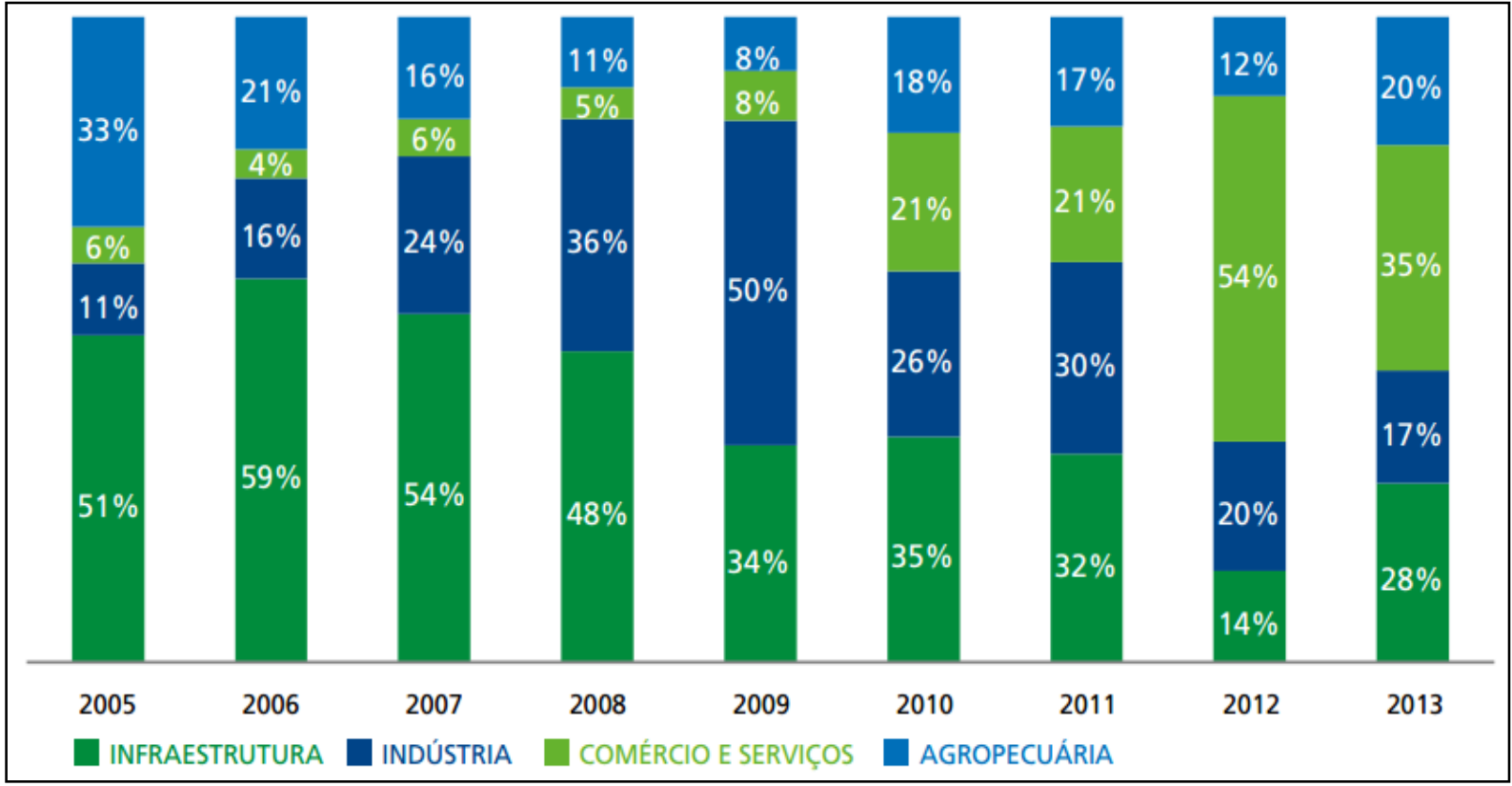

Fonte: IBGE, 2014. BNDES, 2014. Elaborado pelo autor.

Dentre os principais projetos colocados em prática na região ao longo do período em análise (2005-2013), nota-se que de 2005 a 2008 os investimentos se deram majoritariamente no setor de infraestrutura, e de 2009 a 2013 as maiores porcentagens de desembolsos se intercalaram entre indústria, infraestrutura e comércio e serviços. Esses investimentos foram, em grande parte, responsáveis pelo melhoramento da estrutura que impulsionou o desenvolvimento econômico da região ${ }^{7}$. Assim, tais investimentos contribuem para a criação e aperfeiçoamento de arranjos espaciais produtivos, na medida em que criam uma gama de possibilidades de interligar os locais através dos sistemas de comunicação e transporte.

No setor de infraestrutura, por exemplo, embora o gargalo no transporte da produção de grãos da região ainda é um grande problema, houveram grandes quantidades investidas em vista de amenizar os problemas de transporte que historicamente a região apresenta. No Mato Grosso, a conclusão da pavimentação da BR-163 em toda a extensão do estado e a chegada dos trilhos de trem no maior terminal rodoferroviário da América Latina, situado em Rondonópolis, foram obras de extrema importância para o estado do Mato Grosso e para a região Centro-Oeste.

7 O fato de ter existido desenvolvimento econômico não necessariamente significa dizer que houve desenvolvimento social. São categorias distintas. Mas economicamente, houveram avanços importantes. 
Dessa forma, o papel do Banco Nacional de Desenvolvimento Econômico e Social (BNDES) no desenvolvimento da região Centro-Oeste foi fundamental. Ainda que seja necessário implementar muitas melhorias na região e no estado do Mato Grosso, é preciso afirmar que muitos avanços já aconteceram. Tanto é assim que o estado do Mato Grosso se transformou no maior produtor nacional de grãos (DENTZ, 2018), além de se configurar naquele que possui maior disponibilidade de área para ampliar a produção.

\section{CONSIDERAÇÕES FINAIS}

A indispensável atuação do Estado na promoção do desenvolvimento, sobretudo econômico, na região Centro-Oeste e no estado do Mato Grosso é o marco principal desse artigo. Através dos programas (Polocentro, Sudan, Sudeco, dentre outros) criados ainda no início da segunda metade do século passado, o Centro-Oeste começou sua inserção paulatina com porcentagens cada vez maiores de participação da economia nacional. Mais recentemente, sobretudo a partir dos anos 2000, o papel do BNDES tem sido fundamental nos investimentos que promoveram melhorias infraestruturais na região. Neste contexto, o estado do Mato Grosso se destaca na retenção de parcelas significativas dos desembolsos do BNDES para a região Centro-Oeste.

Em paralelo com outros fatores, tal constatação contribuiu para que o Mato Grosso se transformasse no maior produtor nacional de grãos, com destaque para as culturas de soja, milho, algodão e girassol (CONAB, 2016). Ao mesmo tempo, o BNDES liberou crédito específico para a construção industrial voltada à transformação dos grãos colhidos na região. Neste viés, a implantação de grandes complexos agroindustriais foi fundamental para o desenvolvimento da região. Pode-se dizer que nos três estados da região a cadeia produtiva de carnes (bovina, suína e de frangos) é responsável pela geração de milhares de empregos.

Além disso, o Estado contribuiu para o desenvolvimento econômico em diferentes regiões dos extensos estados que compõe o Centro-Oeste. Como citado no último tópico, no estado de Mato Grosso a atuação do IFMT em todas as porções do estado contribui na capacitação de mão de obra qualificada para atuar no setor agropecuário. Portanto, os investimentos do Estado não apenas fizeram crescer centros que no século passado já se destacavam na região, como também investiu em áreas remotas, visando a descentralização do desenvolvimento das atividades, em sua maioria, ligadas ao agronegócio. Ainda sobre o estado do Mato Grosso, vale inferir que esse desenvolvimento acelerado no setor 
agropecuário se deu não apenas devido aos maciços investimentos feitos pelo Estado, mas sobretudo devido ao favorecimento das condições edafoclimáticas ali contidas. Dentre elas, destacamos: áreas totalmente planas e de fácil mecanização, luz solar em abundância, estação de chuva bem definida, solos possíveis de serem corrigidos e tornados produtivos, migração de agricultores do Sul do Brasil, dentre outros fatores.

No entanto, como característica do sistema capitalista de produção, todo esse desenvolvimento não trouxe apenas benefícios para a região. Sabe-se que o estado de Mato Grosso e a região Centro-Oeste como um todo é marcada fortemente pela concentração fundiária e de renda, o que coloca grande parcela da população em condições de pobreza, ao passo que os fazendeiros são verdadeiros empresários do campo. Em outras palavras, a desigualdade social, embora tenha diminuído nas últimas décadas, é um dos principais problemas encontrados pela região. Tal problema impede avanços importantes no sentido do desenvolvimento humano, com maiores índices de alfabetização, emprego, acesso à saúde, dentre outros.

Portanto, a atuação das políticas de Estado no desenvolvimento da dinâmica produtiva da região Centro-Oeste foi fundamental. Os investimentos feitos, sobretudo pelo BNDES, desencadearam transformações no território, tendo sido o agronegócio o setor que mais se desenvolveu em função desses investimentos. Embora o setor de serviços seja o mais expresso entre os setores da economia que compõe a região Centro-Oeste, vale lembrar que em grande medida esse setor, assim como a indústria, é atrelado ao agronegócio. Isso leva a afirmar que o agronegócio potencializou, nesta região, não apenas a si mesmo, mas também outros setores estratégicos, como a indústria e os serviços. Em grande medida isso ocorre justamente para atender as demandas do agronegócio totalmente moderno, mecanizado e necessitado de mão de obra altamente qualificada. Em paralelo, como apontamos, isso ocorre em uma situação de desigualdade social e econômica, o que confirma a dinâmica capitalista atuando nas frentes de desenvolvimento do agronegócio na região Centro-Oeste como um todo.

\section{REFERÊNCIAS}

BENJAMIN, César (Org.) Inácio Rangel: obras reunidas-v. 1. 3.ed. Rio de Janeiro: Contraponto, 2012. p. 285-356. 
BNDES. Um olhar para o desenvolvimento: Centro-Oeste. Rio de Janeiro, BNDES, 2014. 512p. Disponível em: < https://web.bndes.gov.br/bib/jspui/handle/1408/2881 > Acesso em: 16 abr. 2018.

CAMPOS, M. C. A Embrapa/Soja em Londrina - PR a pesquisa agrícola de um país moderno. 2010. 123 f. Tese (Doutorado em Geografia) - CFH, UFSC, Florianópolis, 2010.

CONAB. Anuário da soja. 2016. Disponível em: < https://www.conab.gov.br/infoagro/safras>. Acesso em: 20 ago. 2018.

CONTINI, E. et al. Evolução recente e tendências do agronegócio. Revista de Política Agrícola, Brasília, CONAB, ano XV, n. 1, jan.-fev.-mar. 2006, p. 5-28. Disponível em: https://seer.sede.embrapa.br/index.php/RPA/article/view/475. Acesso em: 10 mar. 2018.

DENTZ, Eduardo Von. Dinâmica espacial da acumulação de capital do agronegócio: o caso do Mato Grosso. 2018. 201 f. Dissertação (Mestrado em Geografia) - Universidade Estadual do Oeste do Paraná, Francisco Beltrão, PR, 2018.

DELGADO, Guilherme. Capital financeiro e agricultura no Brasil. São Paulo, ÍconeUNICAMP, 1985.

ESPÍNDOLA, C. J.; CUNHA, R. C. C. A dinâmica geoeconômica recente da cadeia produtiva de soja no Brasil e no Mundo. Geotextos, v. 11, n. 1, p. 217-238, Salvador, UFBA, 2015.

https://portalseer.ufba.br/index.php/geotextos/article/view/12692/9733>. Acesso em: 23 mai. 2018.

GRAZIANO DA SILVA, José. A modernização dolorosa: estrutura agrária fronteira agrícola e trabalhadores rurais no Brasil. Rio de Janeiro: Zahar, 1982. 192 p.

GRAZIANO DA SILVA, José. A nova dinâmica da agricultura brasileira. 2 ed. Unicamp, 1998.

GUANZIROLI, Carlos Enrique. Agronegócio no Brasil: perspectivas e limitações. Revista Economia - textos para discussão, UFF-RJ, n. 186. Abril/2006.

SANTOS, Camila Dutra dos. Difusão do agronegócio e reestruturação urbano-regional no Oeste baiano. 2016. 450f. Tese (Doutorado em Geografia). Universidade Estadual do Ceará, Centro de Ciências e Tecnologia, Programa de Pós-graduação em Geografia, Fortaleza, 2016.

SILVA, Lilian Leandra. O papel do estado no processo de ocupação das áreas de cerrado entre as décadas de 60 e 80. Revista on line Caminhos de Geografia. n. 1. p. 24-36, UFU. Dez/ 2000. Disponível em: <http://www.seer.ufu.br/index.php/caminhosdegeografia/article/viewFile/15251/8552>. Acesso em: 18 mai. 2018.

Recebido em Julhode 2018

Aprovado em Novembrode 2018

Publicado em Fevereiro de 2019 